\title{
Comparison Between Phenylephrine, Ephedrine And Mephentermine In Preventing Hypotension During Spinal Anesthesia For Caesarean Section And Their Effect On Fetal Outcome.
}

\author{
Dr Sarika Sudhir Lonkar ${ }^{1}$, Dr Sonal Sagar Khatavkar ${ }^{2}$ \\ Dr W S Thatte ${ }^{3}$, Dr Naramaneni Santhi ${ }^{4}$
}

\begin{abstract}
Department Of Anesthesia, Dr D Y Patil Medical College, Hospital And Research Centre Pimpri, Pune, Maharashtra, India ${ }^{1,2,3,4}$
\end{abstract}

\begin{abstract}
Aim: To compare of the efficacy and safety of prophylactic bolus doses of intravenous Phenylephrine, Ephedrine, and Mephentermine for maintenance of arterial pressure during spinal anesthesia in caesarean section and their effects on neonate.

Settings and Design: The present Prospective Randomized study was carried out in a tertiary care teaching hospital. A total of 90 pregnant women posted for elective caesarean section under spinal anesthesia were enrolled and randomly divided into three groups. Group P (phenylephrine) Group E (ephedrine) Group M (mephentermine) with 30 patients in each group.

Materials and Methods: Group E received prophylactic bolus of ephedrine $6 \mathrm{mg} I V$, group M $6 \mathrm{mg} I V$ mephentermine and group P $100 \mathrm{mcg} I V$ of phenylephrine at the time of subarachnoid block. Hemodynamic variables like blood pressure and heart rate were recorded every 2 minutes up to delivery of baby and then every 5 minutes. Neonatal outcome was assessed using Apgar score at 1 and 5 minutes and neonatal umbilical cord blood $\mathrm{pH}$ values.

Statistical Analysis Used: Comparitibility of groups are analyzed with analysis variance test to analyzed parametric data ' $P$ ' value $<0.05$ was considered significant.

Results: There was no difference found in managing hypotension between three groups. The differences in umbilical cord pH and Apgar score between three groups were found statistically insignificant.

Conclusion: All the three vasopressors were equally effective in maintaining maternal blood pressure when given prophylactically $I V$ bolus at the time of $S A B$, without any detrimental effects on fetal and maternal outcome though phenylephrine has quicker peak effect in comparison.
\end{abstract}

Keywords: phenylephrine, ephedrine, mephentermine, hypotension, spinal anesthesia, caesarean section

\section{Introduction}

Anesthesia to a parturient is not only unique but requires highest degree of care. Maternal hypotension after spinal anesthesia for caesarean delivery causes placental hypo perfusion, impaired fetal oxygenation with asphyxial stress, and fetal acidosis. ${ }^{1}$ For the mother, hypotension is especially associated with nausea and vomiting and in more severe cases there may be risk of decreased consciousness pulmonary aspiration, respiratory depression, and cardiac arrest. ${ }^{2}$ The incidence of hypotension during caesarean section under spinal anesthesia has been reported to be $80-90 \%$ or greater depending on the definition used., ${ }^{3,4}$ Vasopressors are required to correct hypotension quickly ${ }^{3,5}$ Vasopressors which have been used in obstetrics primarily include the directly acting selective $\alpha 1$ receptors agonists, phenylephrine and methoxamine, and both directly and indirectly acting mephentermine, metaraminol and ephedrine. ${ }^{6,7}$

Giving vasopressor after maternal systolic blood pressure (SBP) started to decrease causes initial periods of uncorrected hypotension resulting in placental hypoperfusion. ${ }^{8,9}$ Recent studies have shown that any degree of maternal hypotension following spinal anesthesia is undesirable and the best strategy is liberal use of vasoconstrictors to maintain SBP at $100 \%$ of baseline. ${ }^{10}$ This strategy gives the best outcome for the baby (highest umbilical artery $\mathrm{pH}$ ) and the mother (less nausea). ${ }^{8,10,11,12}$ We hypothesized that regardless of the vasopressor chosen, maintaining SAB at $100 \%$ baseline by prophylactic administration of a vasopressor would be more beneficial for the mother and baby.

Safety and efficacy of ephedrine in obstetric patients is supported by animal studies. ${ }^{13}$ Recent clinical studies have shown that ephedrine causes a dose-related propensity to depress fetal $\mathrm{pH}$ and base excess. ${ }^{1}$

Mephentermine is direct and indirect sympathomimetic action and probably the increase in arterial blood pressure is chiefly by increased cardiac output. This may be favorable for placental circulation. However, 
not much information is available in the literature regarding its placental transfer and fetal metabolic effects. ${ }^{14}$ However, a few studies have shown that mephentermine is as effective as phenylephrine in preventing maternal hypotension after spinal anesthesia and has similar effect on neonatal outcome. ${ }^{14}$

In choosing an appropriate vasopressor in obstetrics, a number of factors like efficacy for maintaining blood pressure, no cardiovascular maternal effects, ease of use, direct and indirect fetal effects, cost, and availability need to be considered. ${ }^{7}$ The ideal vasopressor would be one which has rapid onset, short duration of action, easily titrable, reliable and easy to use prophylactically and lack of any adverse maternal and fetal impact.

The present study was designed to assess the effectiveness of phenylephrine, ephedrine and mephentermine in preventing and treating hypotension in spinal anesthesia for caesarean section and their effect on fetal outcome.

\section{Materials And Methods}

After approval by the Institute Ethics Committee we enrolled 90 ASA I and II patients between age 2030 years scheduled for elective caesarean delivery under subarachnoid block. Prior to surgery each patient was examined and a thorough medical history taken with emphasis on respiratory and cardiovascular systems. Potential participants with intercurrent medical diseases like diabetes mellitus, hypertension, pulmonary tuberculosis, asthma, epilepsy, patients with a history of allergy to the study drugs, anatomical deformity of the vertebrae, severe maternal hypovolemia, coagulation disorders, localized infection over the injection site, neurological disorders, severe congenital or acquired heart disease were excluded from the study. A history of pre-eclampsia, cerebrovascular diseases, gestational diabetes, placenta previa and abruption placenta were considered exclusion criteria. Only women with singleton pregnancy beyond 36 weeks gestation without known fetal abnormalities scheduled for elective caesarean section were included in this randomized, double-blind study and written informed consent was taken from all the patients.

Using computer generated random allocation chart, patients were randomly divided into three groups according to the drug to be used. Group E received prophylactic bolus of ephedrine $6 \mathrm{mg}$ IV at the time of intrathecal block, plus rescue boluses of $6 \mathrm{mg}$ ephedrine. Group M received prophylactic bolus of $6 \mathrm{mg}$ IV mephentermine at the time of intrathecal block, plus rescue boluses of $6 \mathrm{mg}$ mephentermine. Group $\mathrm{P}$ received prophylactic bolus of $100 \mathrm{mcg}$ IV of phenylephrine at the time of intrathecal block, plus rescue boluses of 50 mcg phenylephrine.

In order to maintain blinding, the vasopressor solutions were prepared in identical syringes by an anesthetist who was not involved in study. The intraoperative monitoring and postoperative observation is done by the same anesthesiologist who will be administering the drug but unaware of the content of the syringes.

All patients received oral premedication with ranitidine $150 \mathrm{mg}$ the night before the surgery. Preoperatively IV ranitidine $50 \mathrm{mg}$ plus metoclopramide $10 \mathrm{mg}$ as premedication one hour prior to surgery. On arrival to the operation theatre, patients had three blood pressure (BP) and heart rate (HR) readings recorded at 3 min intervals while lying comfortably in the bed. The mean of the three readings was recorded as the baseline value for BP and HR. Standard monitoring was included non-invasive blood pressure (NIBP), continuous electrocardiography (ECG), and pulse oximetry

All the patients were preloaded with $10 \mathrm{ml} / \mathrm{kg}$ of ringer lactate over 15 minutes. Subarachnoid block (SAB) was performed with all patients in the sitting position. After skin infiltration with $2 \%$ xylocaine $2 \mathrm{ml}, 26$ G Quincke's needle was inserted at L3-4 vertebral inter-space and once free flow of clear cerebrospinal fluid was obtained hyperbaric bupivacaine $0.5 \%, 11 \mathrm{mg}(2.2 \mathrm{ml})$ was injected over 10-15 seconds. Time of injection of drug was noted and patient was placed in supine position immediately with a left lateral tilt of 15-20 degrees. The sensory block height of T6 was considered appropriate. The highest level of sensory block was assessed by pinprick method $5 \mathrm{~min}$ after the sub arachnoid block. Oxygen $5 \mathrm{~L} / \mathrm{min}$ was administered through venti mask until delivery of the child. Immediately following SAB, patients received a $1 \mathrm{ml}$ bolus of the study drug $(\mathrm{E}=6 \mathrm{mg}, \mathrm{M}$ $=6 \mathrm{mg}, P=100 \mathrm{mcg}$ ).

Hemodynamic variables like blood pressure and heart rate was monitored every 2 minutes up to delivery of baby and then after every 5 minutes. For the purpose of this study, hypotension was defined as a decrease in blood pressure greater than $20 \%$ from baseline. Whenever hypotension occurred, the study drug was given IV. On each occasion when maternal heart rate decreased to below 60 beats per minute (bpm), atropine $0.3 \mathrm{mg}$ IV was administered. The induction delivery and incision delivery interval were recorded. Nausea and vomiting were scored on a scale of $0-2(0=$ none, $1=$ nausea without vomiting, $2=$ vomiting $)$. After delivery, we gave oxytocin $5 \pm 10$ IU by slow IV fluid. The attending pediatrician, who was blinded to the patient's group, assessed Apgar scores 1 and 5 min after delivery and also took umbilical arterial blood samples from a segment of clamped umbilical cord in heparinized syringe and analyzed using a blood gas analyzer.

Statistical analysis

Comparability of groups were analyzed with Analysis of variance (ANOVA) test. Student's twotailed ' $t$ ' test applied to analyzed parametric data. P value $<0.05$ was considered significant. 


\section{Results}

In this study ninety patients were randomly divided into three groups of 30 patients each. The three groups were matched with regard to their age, body weight and duration of surgery [Table 2]. The difference observed in baseline heart rate, systolic, diastolic, and mean blood pressures between three groups was statistically insignificant [Table 3].

There was higher incidence of bradycardia in patients receiving phenylephrine. Fall in pulse rate was 15 to $17 \%$ of baseline in phenylephrine group but not seen in mephentermine and ephedrine group. Four cases of phenylephrine group had to be given Atropine $0.3 \mathrm{mg}$ to manage bradycardia The difference in mean heart rate till delivery compared between two groups immediately after spinal anesthesia, at 2, 4, 6, 8, 10, and 12 minutes was significant while it was insignificant at 0 and 14 minutes $(P$ value $<0.05$ :significant $)$. The difference in mean heart rate compared between two groups at delivery, 5, 10, minutes and at the end of the surgery was insignificant except at delivery and 15 minutes after delivery ( $P$ value $<0.05$ : significant). [Fig 1]

On intergroup comparison rise of diastolic blood pressure at 2, 4, and 6 minutes post study drugs were significantly less in ephedrine group and mephentermine group as compared to the phenylephrine group $(\mathrm{p}<0.05)$. Similarly elevation of systolic arterial pressure in phenylephrine group was significantly higher compared to other two groups for first 6 minutes. No significant differences were observed between changes in systolic and diastolic blood pressure of Ephedrine and Mephentermine group at any time. [Fig 2,3]

Overall, 24/30 (80\%) patients in the phenylephrine group and 14/30 (45\%) patients in ephedrine group and in group M, 17/30 (55\%) had one or more episode of hypotension and required one or more bolus of vasopressor. The number of rescue doses required in three groups were statistically insignificant. [Fig 4] ( $P$ value $<0.05$ : significant).

The difference in birth weight of neonates between three groups was statistically insignificant. No neonate had Apgar score $<7$ at 1 or 5 minute. Mean neonatal umbilical cord $\mathrm{pH}$ in group $\mathrm{p}$ was $7.33 \pm 0.04$; group E 7.34 \pm 0.04 . and 7.30 \pm 0.04 in group M. Patients given phenylephrine had neonates with higher umbilical cord $\mathrm{pH}$ than those given ephedrine but the difference was statistically nonsignificant .Thus there was no significant effect of vasopressors on fetus in terms of umbilical cord blood $\mathrm{pH}$ and APGAR Score at 1 and 5 minutes. [Fig 5]

\section{Discussion}

Caesarean section is one of the most commonly performed operations. With the large number of women undergoing this procedure, it is necessary to consider the inherent risks involved for both mother and child. Regional anesthesia in Caesarean section offers significant benefit over general anesthesia. ${ }^{15}$ Spinal anesthesia is inexpensive and yields symmetric block rapidly. During spinal anesthesia for Caesarean section hypotension is common. Supine hypotension syndrome due to aortocaval compression could deteriorate the hemodynamic effect of spinal anesthesia. The risk to the mother includes symptoms of dizziness, nausea and vomiting due the rapid decline in blood pressure, ${ }^{2}$ while fetal acidosis may be among the fetal consequences of prolonged maternal hypotension. To prevent injury to mother or fetus caused by hypotension, it is customary to treat supine hypotension syndrome quickly and efficiently. It has been shown that the percentage decrease in placental perfusion is related to the percentage reduction in maternal arterial pressure and not to the absolute reduction in pressure.

Several pharmacologic like vasopressors and non-pharmacologic methods like leg elevation, left uterine displacement, preloading have been used for management of hypotension, with no single method adequate or conclusively superior. ${ }^{3,16}$ Despite all conservative measures, routinely, vasopressors such as ephedrine, mephentermine and phenylephrine have been given prophylactically and preoperatively to combat maternal hypotension.

The results of our study showed that regardless of the type of vasopressor, keeping blood pressure to $100 \%$ of baseline has beneficial effects on both mother and the baby. There was no evidence of fetal acidosis and also the APGAR scores were good for all neonates.

We found that all three vasopressors were equally effective in maintaining blood pressure when administered before the onset of hypotension. In our study there were brief periods of hypotension $(<2 \mathrm{~min})$ in all the three groups, which responded to bolus vasopressor treatment. This technique causes reduction in the total dose of the drug administered. Adminietering vassopressors after hypotension causes undesirable effects since the activity of vasopressors administered lagged behind the physiological changes leading to hypotension and larger doses had to be given.$^{17}$ Recent studies have shown that any reduction in maternal blood pressure is undesirable and the goal should be to maintain SBP at hundred percent of base line with liberal use of vasopressors. ${ }^{18}$

In our study all the three vasopressor effectively maintained arterial pressure within $20 \%$ limit of baseline value though phenylephrine maintained better in first $6 \mathrm{~min}$ of bolus dose as compared to ephedrine and mephentermine. This may be due to that, phenylephrine has peak effect within one minute, whereas ephedrine 
and mephentermine has 2-5min. Phenylephrine has quicker control of hypotension and less number of bolus dose are required to manage hypotension than mephentermine and ephedrine.

In our study phenylephrine causes significant reduction in heart rate after the bolus dose, which is a consistent effect in phenylephrine treated women in other studies also. ${ }^{1,4,10,15}$ This is probably due to beta adrenergic effect of ephedrine and mephentermine which the phenylephrine lacks. In spinal anesthesia, since there is decreased venous return, decreased venous pressure and a decreased right heart pressure thus slowing of the heart rate is expected on the basis of the Brain-bridge reflex. Bradycardia is also expected in high spinal, probably due to some paralysis of the cardiac accelerator nerve.

We confirmed in this study that there was no difference between of phenylephrine, ephedrine and mephentermine in their efficacy for managing hypotension following spinal anesthesia in parturient undergoing caesarean delivery in the range of doses that have been studied, also none had effect on neonate. Similar results with regards to maternal hemodynamics and neonatal Apgar scores have been reported by Sahu et al by comparing ephedrine and mephentermine administered as intravenous bolus for the treatment of hypotension associated with spinal anesthesia during caesarean section. ${ }^{19}$ However, they did not study the effect of these drugs on umbilical artery $\mathrm{pH}$.

D V Rama Siva Naik \& Murali Prabhakar found that the phenylephrine, ephedrine and mephentermine are effective in IV bolus form in maintenance of arterial pressure within $20 \%$ limit of base line though phenylephrine has quicker peak effect in comparison to, ephedrine and mephentermine and it causes reduction in heart rate which may be advantageous in cardiac patients and patients in whom tachycardia is undesirable. Apgar score did not reveal any untoward effect on fetal status since all new born of three groups had Apgar score greater than $7 .^{20}$

Anilkumar Ganeshanavar etal administered IV bolus phenylephrine, ephedrine and mephentermine for elective as well as emergency caesarean section under spinal anesthesia who developed hypotension. They concluded that phenylephrine group had quicker control of blood pressure compared to the other two groups. However, as the time elapsed all drugs achieved comparable control of blood pressure. Phenylephrine did show some advantage over others with regard to reduction in heart rate. . However, they did not study the effect of these drugs on umbilical artery $\mathrm{pH}^{21}$

Many studies have reported that ephedrine may not be the ideal drug for managing spinal hypotension in obstetrics and may be associated with greater fetal acidosis than phenylephrine, metaraminol, and angiotensin. $^{22,23,24,25}$, Ephedrine possibly failed because of inadequate dose and inappropriate time of administration.

We were able to maintain good control of SBP with ephedrine probably because we attempted to increase maternal blood pressure before onset of SAB induced hypotension. The recommended dose for IV ephedrine infusion is between $0.5 \mathrm{mg} / \mathrm{min}$ to $5 \mathrm{mg} / \mathrm{min}$. We selected bolus dose of $(6 \mathrm{mg})$, as our target was to keep blood pressure at baseline. We found that with this regime ephedrine was effective in maintaining blood pressure without evidence of fetal acidosis. Using the same infusion rate but a larger bolus (10 $\mathrm{mg})$ after the blood pressure fell to less than $90 \%$ baseline, Kee et al. reported $39 \%$ incidence of fetal acidosis. ${ }^{25}$ This was due to larger initial requirements of ephedrine in first $10 \mathrm{~min}$ after induction of spinal anesthesia. Kansal et al. used $2.5 \mathrm{mg} / \mathrm{min}$ infusion after a $5 \mathrm{mg}$ bolus and reported effective control of maternal blood pressure, no evidence of fetal acidosis and decreased total drug consumption. ${ }^{26}$

Larger doses of ephedrine are associated with maternal symptoms like tachycardia and nausea and vomiting as reported by many authors. ${ }^{26,27}$ We observed an increase in maternal HR in all patients receiving ephedrine but the incidence of nausea and vomiting was low (11.5\%). None of the patients required treatment for this nausea and vomiting.

Prakash et al. found that women who were given phenylephrine had neonates with higher umbilical arterial $\mathrm{pH}$ values than those given ephedrine. There was no difference between two groups in the incidence of true fetal acidosis similar to this study finding. ${ }^{4}$

Cooper et al. concluded in their study that the umbilical artery $\mathrm{pH}$ was similar, whether ephedrine or phenylephrine was used to maintain maternal arterial pressure, which is consistent with this study. Acidotic changes in umbilical artery are sensitive indicators of uteroplacental insufficiency. The study finding is indirect evidence that uterine blood flow may in fact be better with phenylephrine compared with ephedrine. The exact reason how ephedrine causes acidosis is unknown. One of the reasons is that it crosses through placenta and has a direct effect on fetus to cause acidosis. There was no difference in Apgar score between the two groups. In this study, no neonate had an Apgar score $<7$ at 1 or at 5 minutes. ${ }^{27}$

Adigun and Amnaor-Boadu in their study compared intravenous ephedrine with phenylephrine for the maintenance of arterial blood pressure during elective caesarean section under spinal anesthesia. The mean Apgar scores were similar for the two groups; no baby had Apgar score of $<8$ in either group. ${ }^{28}$ The results are in accordance with this study. 


\section{Conclusion}

Phenylephrine, ephedrine and mephentermine are equally efficient in managing hypotension when given prophylactically at the time during spinal anesthesia for elective caesarean delivery. There was no difference between three vasopressors in the incidence of true fetal acidosis. Neonatal outcome remains equally good in all three groups.

In conclusion, maternal hypotension should be aggressively managed to minimize the risk of fetal acidosis, as a definite correlation exists between the maximum decrease in SBP as a percentage of baseline and umbilical arterial $\mathrm{pH}$.

\section{References}

[1]. Lee A, Warwick D, Kee N, Gin T. Trails of ephedrine versus phenylephrine for the management of hypotension during spinal anaesthesia for caesarean section. Anaesth Analg 2002; 94:920-6.

[2]. Balki M, Carvalho JC. Intraoperative nausea and vomiting during cesarean section under regional anesthesia. Int J Obstet Anesth 2005; 14:230-41.

[3]. Cyna AM, Andrew M, Emmett RS, Middleton P, and Simmons SW. Techniques for preventing hypotension during spinal anaesthesia for caesarean section. Cochrane Database Syst Rev 2006; 4:CD002251.

[4]. Prakash S, Pramanik V, Chellani H, Salhan S, Gogia AR. Maternal and neonatal effects of bolus administration of ephedrine and phenylephrine during spinal anaesthesia for caesarean delivery: A randomized study. Int J Obstet Anesth 2010; 19:24-30.

[5]. Loubert C. Fluid and vasopressor management for Cesarean delivery under spinal anesthesia: continuing professional development. Can J Anaesth 2012; 59: 604-19

[6]. Deb Sanjay Nag, Devi Prasad Samaddar, Abhishek Chatterjee, Himanshu Kumar, Ankur Dembla. Vasopressors in obstetric anesthesia: A current perspective World Journal of Clinical Cases 2015 January 16; 3(1): 58-64 ISSN 2307-8960 (online)

[7]. Mitra JK Prevention of Hypotension following Spinal Anaesthesia in Caesarean Section - then and now. Kathmandu Univ Med J 2010; 9(32):415-9

[8]. Ngan Kee WD, Khaw KS, Lee BB, Wong MMS, Ng FF. Metaraminol infusion for maintenance of arterial blood pressure during spinal anaesthesia for cesarean delivery-The effect of crystalloid bolus. Anesth Analg 2001; 93:703-8.

[9]. Kansal A, Mohta M, Sethi AK, Tyagi A, Kumar P. Randomised trial of intravenous infusion of ephedrine or mephentermine for management of hypotension during spinal anaesthesia for caesarean section. Anaesthesia 2005; 60:28-34.

[10]. Ngan Kee WD, Khaw KS, Ng FF. Comparison of phenylephrine infusion regimens for maintaining maternal blood pressure during spinal anaesthesia for Caesarean section. Br J Anaesth 2004; 92:469-74.

[11]. Ngan Kee WD, Khaw KS, Ng FF. Prevention of hypotension during spinal anesthesia for cesarean delivery. An effective technique using combination phenylepherine infusion and crystalloid co-hydration. Anesthesiology 2005; 103:744-50.

[12]. Ngan Kee WD, Khaw KS, Ng FF, Lee BB. Prophylactic phenylephrine infusion for preventing hypotension during spinal anaesthesia for cesarean delivery. Anesth Analg 2004; 98:815-21.

[13]. Ralston DH, Shnider SM, deLorimier AA. Effects of equipotent ephedrine, metaraminol, mephentermine, and methoxamine on uterine blood flow in the pregnant ewe. Anesthesiology 1974; 40:354-70.

[14]. M.Mohta, S.Sai Janani, A.K.Sethi. Comparision of phenylephrine hydrochloride and mephentermine sulphate for prevention of post spinal hypotension; Journal of the Association of Anaesthetists of Great Britain and Ireland. 2010; 65: 1200-1205.

[15]. Clyburn P. Spinal anaesthesia for caesarean section: time for reappraisal? (Editorial) Anaesthesia 2005; 60:633-3.

[16]. Loubert C. Fluid and vasopressor management for Cesarean delivery under spinal anesthesia: continuing professional development. Can J Anaesth 2012; 59: 604-19.

[17]. Macarthur A, Riley ET. Obstetric Anesthesia controversies: Vasopressor choice for postspinal hypotension during cesarean delivery. Int Anesthesiol Clin 2007; 45:115-32.

[18]. Ngan Kee WD, Lau TK, Khaw KS, Lee BB. Comparison of metaraminol and ephedrine infusion for maintaining arterial pressure during spinal anaesthesia for elective cesarean section. Anesthesiology 2001; 95:307-13

[19]. Dr. Dinesh Sahu, Dr. Dilip Kothari and Dr. Amrita Mehrotra "Comparison of bolus phenylephrine, ephedrine and mephentermine for maintenance of arterial pressure during spinal anaesthesia in caesarean section- a clinical study". Indian J. Anaesth. 2003; 42(2) $125-12$

[20]. DR D V Rama Siva Naik, Dr Murali Prabhakar. Comparison of Intravenous Bolus Ephedrine Phenylephrine and Mephentermine for Maintenance of Arterial Pressure during Spinal Anaesthesia in Caesarean Section. INDIAN JOURNAL OF APPLIED RESEARCH 2015; 5(2) 2249-555

[21]. Anilkumar Ganeshnavar, Ambi Uday S, Adarsh E.S. Comparison of Bolus Phenylephrine, Ephedrine and Mephentermine for Maintenance of Arterial Pressure during Spinal Anaesthesia in Caesarean Section; Journal of Clinical and Diagnostic Research. 2011; 5(5): 948-952.

[22]. Lee A, Ngan Kee WD, Gin T. Prophylactic ephedrine prevents hypotension during spinal anesthesia for cesarean delivery but does not improve neonatal outcome: A quantitative systematic review. Can J Anaesth 2002; 49:588-99.

[23]. Cooper DW, Carpenter M, Mowbray P, Desira WR, Ryall DM, Kokri MS. Fetal and maternal effects of phenylepherine and ephedrine during spinal anaesthesia for cesarean delivery. Anesthesiology 2002; 97:1582-90.

[24]. Lee A, Ngan Kee WD, Gin T. A quantitative systematic review of randomized controlled trials of ephedrine versus phenylephrine for the management of hypotension during spinal anaesthesia for cesarean delivery. Anesth Analg 2002; 91:920-6.

[25]. Ngan Kee WD, Lau TK, Khaw KS, Lee BB. Comparison of metaraminol and ephedrine infusion for maintaining arterial pressure during spinal anaesthesia for elective cesarean section. Anesthesiology 2001; 95:307-13.

[26]. Kansal, M. Mohta, A. K. Sethi, A. Tyagi and P. Kumar, Randomised trial of intravenous infusion of ephedrine or mephentermine for management of hypotension during spinal anaesthesia for Caesarean section. Anaesthesia, 2005; 60: 28-34

[27]. Cooper DW, Sharma S, Orakkan P. Retrospective study of association between choice of vasopressor given during spinal anaesthesia for high risk caesarean delivery and fetal pH. Int J Obstet Anesth 2010; 19:44-9.

[28]. Adigun TA, Amanor-Boadu SD, Soyannwo SD. Comparison of intravenous ephedrine with phenylephrine for the maintenance of arterial blood pressure during elective caesarean section under spinal anaesthesia. Afr J Med Med Sci 2010; 39:13-20. 
Comparison Between Phenylephrine, Ephedrine And Mephentermine In Preventing...

Table 1 Comparative analysis of three vasopressors

\begin{tabular}{|c|c|c|c|c|}
\hline $\mathbf{S r}$ & Drug & Mechanism of action & Advantage & Disadvantage \\
\hline 1 & Phenylephrine & $\begin{array}{l}\text { Selective } \alpha 1 \text { receptor agonist at } \\
\text { clinical doses, increasing systemic } \\
\text { vascular resistance secondary to } \\
\text { vasoconstriction }\end{array}$ & $\begin{array}{l}\text { Immediate onset and } \\
\text { short duration of action } \\
10-15 \text { minutes Ideal for } \\
\text { continuous infusion }\end{array}$ & $\begin{array}{l}\text { Tachyphylaxis. } \\
\text { Reflex bradycardia and } \\
\text { serial dilution for IV } \\
\text { administration is source of } \\
\text { error }\end{array}$ \\
\hline 2 & Ephedrine & $\begin{array}{l}\alpha \text { and } \beta \text { receptor agonist. } \\
\text { Both direct and indirectly acting, } \\
\text { clinical effect is primarily due to its } \\
\text { indirect action of releasing } \\
\text { norepinephrine from postganglionic } \\
\text { nerve endings }\end{array}$ & $\begin{array}{l}\text { Economical and does } \\
\text { not need multiple } \\
\text { dilutions as compared to } \\
\text { Phenylephrine. No } \\
\text { bradycardia }\end{array}$ & $\begin{array}{l}\text { Tachyphylaxis. } \\
\text { Tachycardia, } \\
\text { Adverse effect on fetal acid- } \\
\text { base status as } \\
\text { compared to Phenylephrine, } \\
\text { delayed onseSSt of action, } \\
\text { longer duration of action of } \\
\text { about } 60 \text { min }\end{array}$ \\
\hline 3 & Mephenteramine & $\begin{array}{l}\alpha \text { and } \beta \text { receptor agonist. } \\
\text { Both direct and indirectly acting }\end{array}$ & $\begin{array}{l}\text { Economical and does } \\
\text { not need multiple } \\
\text { dilutions as compared to } \\
\text { Phenylephrine, } \\
\text { immediate onset of } \\
\text { action peaking at } 5 \mathrm{~min} \\
\text { and lasting } 15-30 \mathrm{~min}\end{array}$ & $\begin{array}{l}\text { Tachyphylaxis. Little } \\
\text { evidence available on } \\
\text { placental transfer and its } \\
\text { fetal metabolic impact }\end{array}$ \\
\hline
\end{tabular}

Table 2 Comparison of baseline heart rate, systolic, diastolic and mean blood pressure

\begin{tabular}{|l|c|c|c|}
\hline Characteristics & Group P & Group E & Group M \\
\hline Heart rate & $90.32 \pm 16.65$ & $87.38 \pm 13.03$ & $97.3 \pm 19$ \\
\hline Systolic blood pressure & $120.24 \pm 12.35$ & $120.44 \pm 9.84$ & $126.8 \pm 7.7$ \\
\hline Diastolic blood pressure & $78.32 \pm 9.90$ & $76.16 \pm 9.30$ & $78.8 \pm 5.8$ \\
\hline Mean blood pressure & $90.30 \pm 10.07$ & $92.92 \pm 8.85$ & $94.24 \pm 8.20$ \\
\hline
\end{tabular}

Table 3 Patients characteristic and relevant data

\begin{tabular}{|l|c|c|c|}
\hline \multicolumn{1}{|c|}{ Parameter } & Phenylephrine & Ephedrine & Mephentermine \\
\hline Maternal age (Mean \pm SD) yrs. & $24.5 \pm 3.1$ & $24.2 \pm 3.9$ & $62.7 \pm 1.3$ \\
\hline $\begin{array}{l}\text { Maternal weight (Mean } \pm \text { SD) } \\
\text { kgs }\end{array}$ & $62.7 \pm 1.7$ & $63 \pm 1.26$ & $65.2 \pm 6.4$ \\
\hline $\begin{array}{l}\text { Maternal height (Mean } \pm \text { SD) } \\
\text { inches }\end{array}$ & $65.5 \pm 4$ & $62 \pm 4.8$ & T6 \\
\hline $\begin{array}{l}\text { Level of sensory height } \\
\text { (median) }\end{array}$ & T6 & T6 & $590 \pm 64$ \\
\hline $\begin{array}{l}\text { SAB- Del interval (Mean } \pm \text { SD) } \\
\text { sec }\end{array}$ & $571 \pm 63$ & $634 \pm 64$ & $61 \pm 10$ \\
\hline $\begin{array}{l}\text { UI }- \text { Del interval (Mean } \pm \text { SD) } \\
\text { sec. }\end{array}$ & $56 \pm 9$ & $64 \pm 14$ & \multirow{2}{*}{} \\
\hline
\end{tabular}

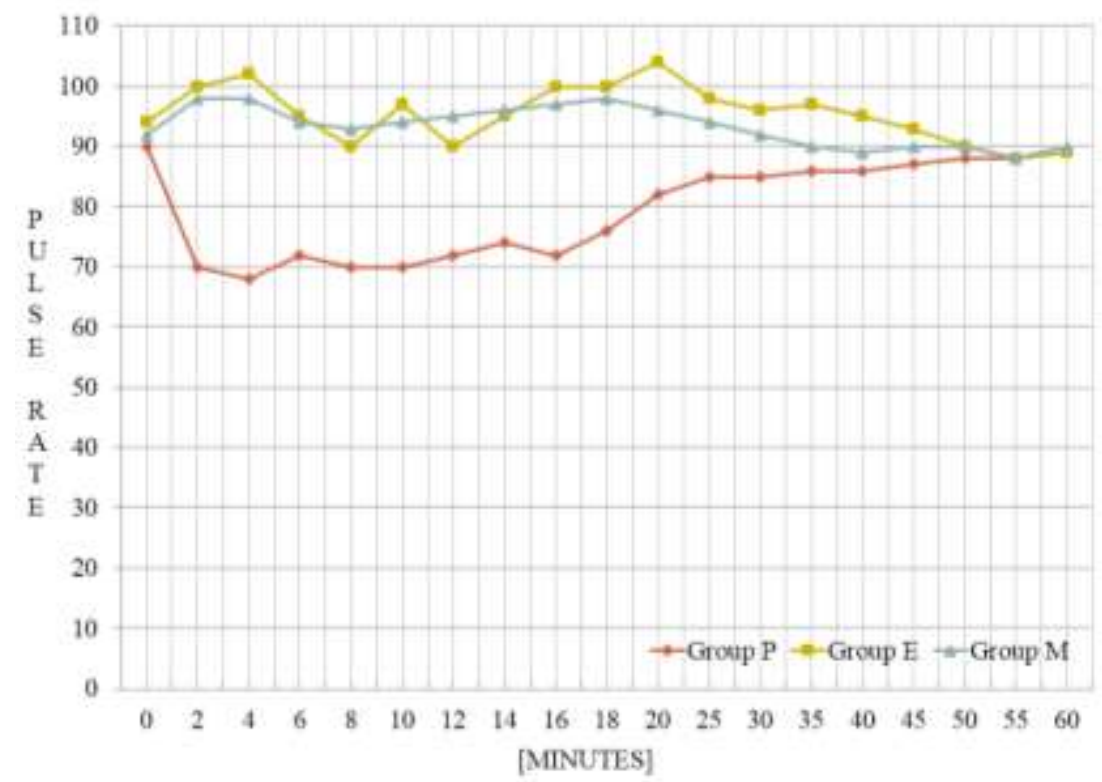

Fig 1 Comparison of pulse rate between three groups 


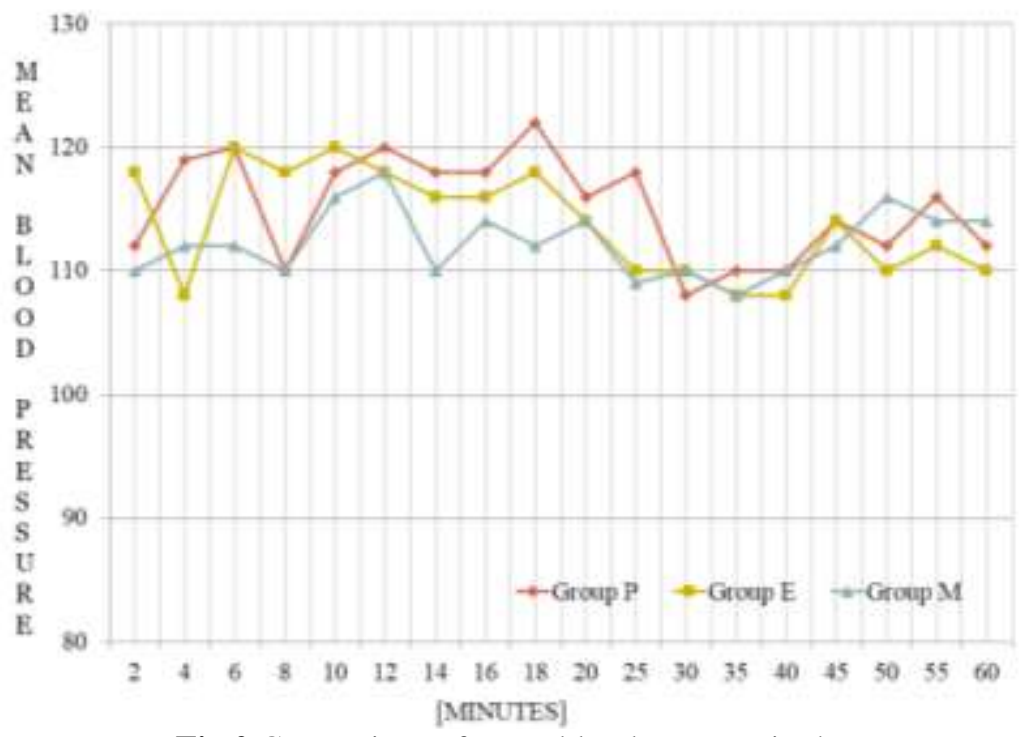

Fig 2 Comparison of mean blood pressure in three groups

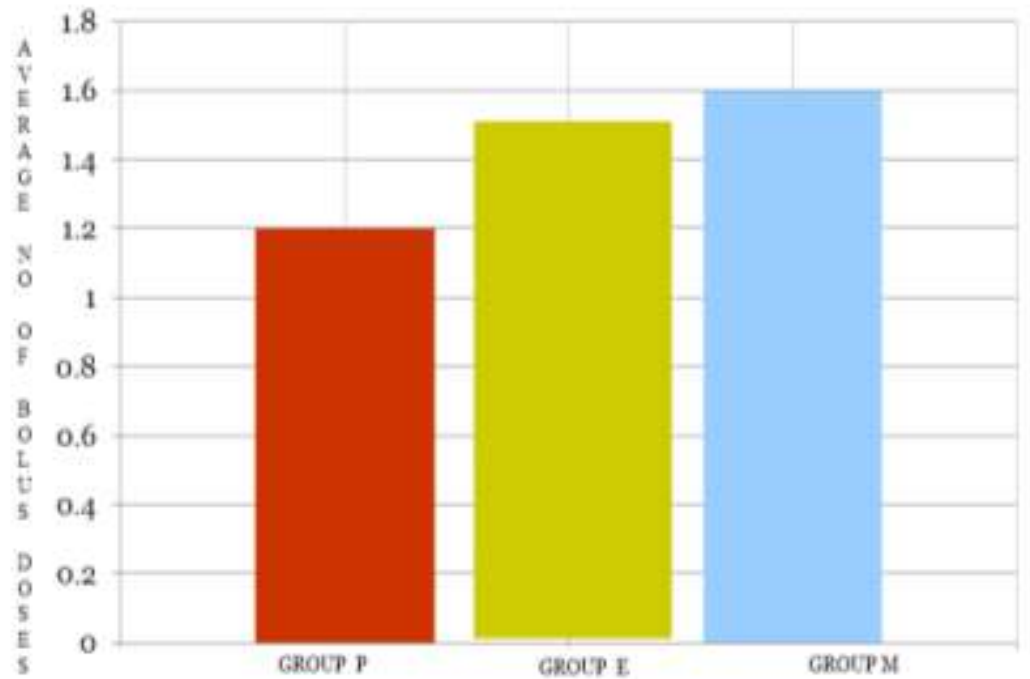

Fig 3 Bar diagram showing number of bolus doses in three groups

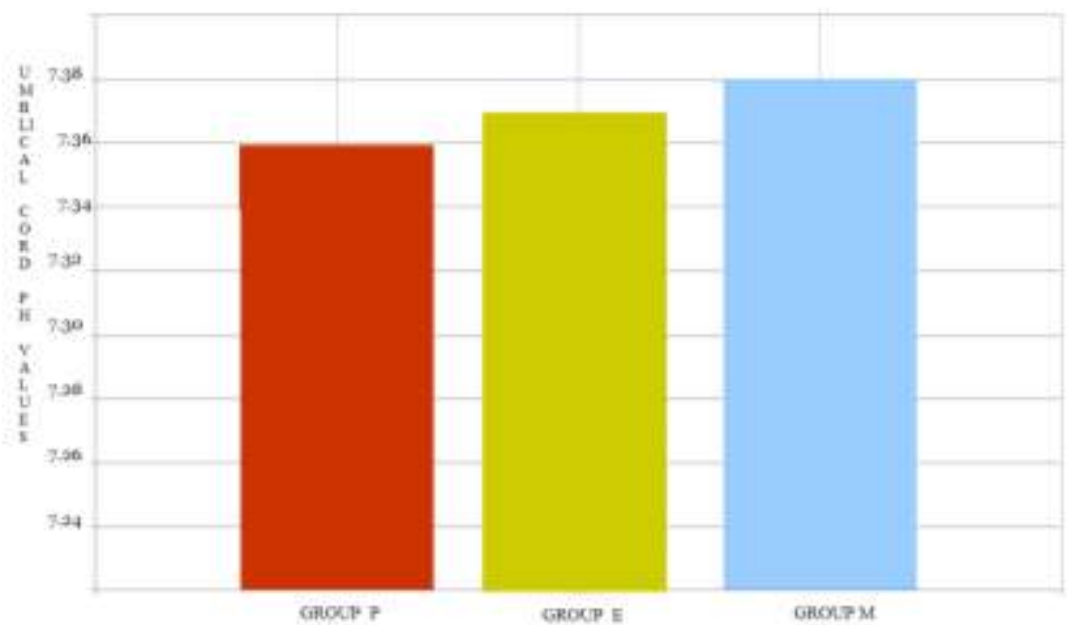

Fig 4 Bar diagram showing umbilical cord blood $\mathrm{pH}$ in three groups 